\title{
Menstrual Hygiene Practice and Associated Factors among Secondary School Girls in Wegera District, Northwest Ethiopia; a Cross-Sectional Study
}

\author{
Meseret Abay Fisseha ${ }^{1,}$, , Yigzaw Kebede ${ }^{2}$, Hedija Yenus Yeshita $^{3}$ \\ ${ }^{1}$ Department of Reproductive Health, School of Public Health, Mekelle University, Mekelle, Ethiopia \\ ${ }^{2}$ Department of Epidemology and Biostatistics, College of Medicine and Health Science, University of Gondar, Gondar, Ethiopia \\ ${ }^{3}$ Department of Reproductive Health, Institute of Public Health, University of Gondar, Gondar, Ethiopia
}

Email address:

mesiabay@gmail.com (M. A. Fisseha),gkyigzaw@yahoo.com (Y. Kebede), kedijayenus@yahoo.com (H. Y. Yeshita)

${ }^{*}$ Corresponding author

\section{To cite this article:}

Meseret Abay Fisseha, Yigzaw Kebede, Hedija Yenus Yeshita. Menstrual Hygiene Practice and Associated Factors among Secondary School Girls in Wegera District, Northwest Ethiopia; a Cross-Sectional Study. Computational Biology and Bioinformatics.

Vol. 5, No. 1, 2017, pp. 6-11. doi: 10.11648/j.cbb.20170501.12

Received: March 1, 2017; Accepted: March 23, 2017; Published: April 15, 2017

\begin{abstract}
Menstrual hygiene is an issue that is insufficiently acknowledged and has not received adequate attention. There is a substantial knowledge gap on menstrual hygiene among adolescent girls. Lack of knowledge and poor personal hygienic practices during menstruation can lead to various gynecological problems. This study aimed to assess menstrual hygine practice and factors associated with it among secondary school girls in Wegera District, Northwest Ethiopia. A school-based cross-sectional study was conducted among 423 randomly selected secondary school girls from March to April, 2014. The data were collected by using pre-tested self -administered questionnaire. Good menstrual hygiene practice was found to be $29.8 \%$. Menstrual practice among girls who had exposure to advertisement on sanitary napkins (AOR 2.06(1.27, 3.34)) and good knowledge on menstrual hygiene (AOR 2.23(1.06, 4.71)) were the factors associated with good menstrual hygiene practice. This study revealed that the menstrual hygiene practice of secondary school girls was low. Exposure to advertisement regarding sanitary napkins and knowledge on menstrual hygiene were found to influence their practice towards menstrual hygiene. Menstrual hygiene is an issue needs to be addressed at all levels.
\end{abstract}

Keywords: Knowledge, Practice, Menstrual Hygiene, Ethiopia

\section{Background}

Globally, females of reproductive age account $26 \%$ of the total population. Most of these women and girls menstruate monthly in their reproductive life span [1]. Menstruation is part of the female reproductive cycle that starts at puberty and menstrual hygiene is fundamental to the dignity and wellbeing of women and girls and an important part of the basic hygiene, sanitation and reproductive health services to which every woman and girl has a right. Even though menstruation is a natural process, it is linked with several misconceptions and malpractices which may result in adverse health outcomes. And also, menstrual hygiene management has not received adequate attention by professionals in the health and education sectors [2].

Menstrual hygiene refers to personal hygiene during menstruation. This includes bathing at least once a day, wearing clean and regularly changed undergarment and using proper absorbent materials like pads and tampons which are also changed regularly (every three to four hours) [3-6].

To women and girls in the developed world these requirements are taken for granted. But in developing societies difficult to fullfil the requirements [7-9]. In India, a cross-sectional study on school going adolescent girls in rural area, majority of the girls were using cloth (46.67\%) and only $15.67 \%$ were using sanitary napkins [10]. Similarly a study of adolescent girls in Rajasthan 19.5\% reported using readymade sanitary pads during menstruation [11].

Since menstruation is considered as a taboo to discuss with 
others, young girls often grow up with limited knowledge about how to take a good care of personal hygiene. Adult women may themselves not be aware of the biological facts or good hygienic practices, instead passing on cultural taboos and restrictions to be observed [2, 3]. A study done on comparison of the menstruation and education experiences of girls in Africa reported $84 \%$ of girls in Afghanistan never wash their genital areas, where as $80 \%$ of girls in Afghanistan use water but no soap for washing their menstrual protection and $30 \%$ of girls in Malawi do not use the latrine when menstruating. This was also noted by $20 \%$ of women in communities in India [12, 13]. A study in Nigeria on the practice of menstrual hygiene of girls $73(60 \%)$ changed sanitary pads three times a day,whereas similar studies reported $11 \%$ of girls in Ethiopia and $60 \%$ of girls in India only change their menstrual cloths once a day $[2,14]$.

Different studies reported that there are different factors which affect menstrual hygiene practices. Good menstrual hygiene was practiced among girls whose parents were literate, older girls, having premenstrual preparation, girls' studing in secondary schools and above, exposure to adivertisements regarding usage of sanitary pads in mass media and socioeconomic status of the family [11, 15-18]. Study reported in an urban slum of Mumbai, Significant association was observed between having good/fair knowledge and good practices. Among girls with having good/fair knowledge, $91 \%$ had good practice $(\mathrm{p}<0.01)$. Similarly a study in Nigeria found the association between knowledge of menstruation and menstrual hygiene practice $(\mathrm{p}<0.05)[14,17]$.

In Ethiopia, like in many parts of developing world, the subject of menstruation and puberty hygiene is rarely discussed at home as well as at schools. This could be mainly due to some cultural restrictions preventing the flow of correct and sufficient information given to youngsters. Girls in rural Ethiopia also expressed a hesitancy to buy sanitary pads in public shops due to the cultural or social implications of becoming a woman in Ethiopian society (e.g. readiness to marry and have children) [12].

Although good menstrual hygiene practice is good to live healthy, productive and dignified live, little is known about menstrual hygiene and its associated factors among female students in Ethiopia. Therefore, it is important to identify the practice of menstrual hygiene and associated factors among school going students to intervene accordingly. So, this study was conducted to determine the level of menstrual hygiene practices and factors associated with good menstrual hygiene practice among secondary school girls in Wegera district, Northwest Ethiopia.

\section{Methods}

\subsection{Study Design and Set Up}

A school based cross sectional study was conducted in March 2014 among 423 secondary school girls at Wegera district. Wogera district is located $35 \mathrm{~km}$ away from Gondar
Town; the capital city of North Gondar Zone, Northwest Ethiopia. Under this district there are two secondary schools and during the 2013/14 academic year 2,202 female students enrolled in those secondary schools.

\subsection{Sample Size Determination and Sampling Techniques}

The sample size was determined by using single population proportion formula with the assumptions of $95 \%$ confidence interval, marginal error of $(d=5 \%)$, and by considering the proportion of students who practiced good menstrual hygiene $50 \%$ since there were no other studies done in the country, and considering $10 \%$ non response rate the final sample size becomes 423. A simple random sampling was done to select girls on both secondary schools who were menstruating atleast one time before data collection.

\subsection{Data Collection Tools and Procedures}

The data were collected by self-administered technique, using a questionnaire adapted from relevant literatures of similar studies. It consists of basic socio demographic characteristics, source of information about menstrual hygiene and information concerning the knowledge and practice of menstrual hygiene. Respondents who scored 4-6 points were adjudge as having good practice and respondents who scored 0-3 points were adjudged as having poor practices.

\subsection{Data Analysis Procedures}

The collected data was entered into EPI Info version 3.5.1 software and exported into SPSS version 16 software for analysis. Missing values, outliers and normality of data were checked by data exploration. Proportion and bivariate analysis were carried out. Variables with p-value $<0.2$ at bivariate level were further fited to multivariate logistic regression to control the effect of confounding variable.

\subsection{Operational Definitions}

Knowledge of menstrual hygiene: To measure the respondent's knowledge of menstrual hygiene there are 10 questions with each correct answer attracting 1 point and 0 for incorrect or don't know. Respondents that scored $8-10$ points were considered as having good knowledge, respondants that scored $4-7$ points were considered as having fair knowledge while a score of less than 3 points as poor knowledge as similarly described by previous study [19].

Menstrual Hygiene practice: The measurement of practice of menstrual hygiene focus on use of material during menstruation (assign 1 point for use of sanitary pad, 0 for other sanitary materials), methods of disposal of materials $(0$ for open field, 1 for other proper disposal), cleaning of external genitalia ( 1 for cleaning 2 or more times/day, 0 for $<2$ times/day), frequency of sanitary pad change (1 for changing pad 2 or more times/day, 0 for $<2$ times/day) an materials used for cleaning purpose (1 for washing with soap and water or with plain water, and 0 for not washing). 
Respondents who scored 4-6 points were adjudge as having good practice and respondents who scored 0-3 points were adjudged as having poor practices as similarly described in previous study [19].

\subsection{Ethical Considerations}

The proposal was reviewed and approved by the institutional review Board (IRB) of university of Gondar. Following the endorsement by the research review committee, the selected district was informed about the objective of the study through a support letter from institute of public health. Each study participant was adequately informed about the purpose, anticipated benefit and risk of the study and their right to discontinue or refuse to participate in the study. Informed written consent was obtained from each study participants and consent from parents/guardians was taken for those with age $<18$ years and their confidentiality, privacy and anonymity was maintained.

\section{Result}

\subsection{Socio-Demographic Characteristics of the Study Participants}

Of the 423 study samples, large proportions $(56.7 \%)$ of the study population were in the age group of $16-17$ years. The mean age of the students was 17 years $(\mathrm{SD}=1.5)$. The mean age at menarche of the study participant's was $15 \pm 1.08$ years.

Among the participants $52 \%$ were currently studying in grade 9 and $97.2 \%$ were orthodox Christian. Among the respondants, $237(56 \%)$ got permanent pocket mo ney from their family members where as $51(12 \%)$ of them earn the money by themselves. (Table 1)

Table 1. Socio-demographic characteristics of secondary school girl students, in Wegera District, 2014.

\begin{tabular}{lll}
\hline Socio-demographic characteristics & Number $\mathbf{( n = 4 2 3 )}$ & Percent $(\%)$ \\
\hline Age & & \\
$14-15$ & 63 & 14.9 \\
$16-17$ & 240 & 56.7 \\
$>=18$ & 120 & 28.4 \\
Grade level & & \\
9 & 220 & 52.0 \\
10 & 203 & 48.0 \\
Marital status & & \\
Single & 392 & 92.7 \\
Married & 24 & 5.7 \\
Separated & 6 & 1.4 \\
Widowed & 1 & .2 \\
Religion & & \\
Orthodox & 411 & 97.2 \\
Muslim & 8 & 1.9 \\
Protestant & 2 & .5 \\
Other & 2 & .5 \\
Education of the father & & \\
Illiterate & 168 & 39.7 \\
Literate & 255 & 60.3 \\
Education of the mother & & 66.7 \\
Illiterate & 282 & 33.3 \\
Literate & 141 & \\
\hline & & \\
\hline & &
\end{tabular}

\subsection{Knowledge on Menstruation and Menstrual Hygiene}

Majority of the girls (81.6\%) knew about menstruation before they had menarche. The dominant source of information and advice for the girls were mothers (46.3\%).

The main material known by $232(54.8 \%)$ respondents were commercially made sanitary pad. Three hundred therty two $(78.5 \%)$ respond that menstrual blood is unhygienic. Two hundred ninety two $(69.3 \%)$ participants aware that poor menstrual hygiene predisposes for infection. Two hundred nine $(49.4 \%)$ participants respond that personal hygiene has a role in prevention of menstrual pain. In summary one hundred forty five (34.3\%) study participant had good knowledge about menstrual hygiene, 131(31\%) and $147(34.8 \%)$ respondents had fair and poor menstrual hygiene knowledge respectivelly. The girls expressed their preferred source of information on menstrual matter. Thus, most of them preferred to get from their mother's 248(58.6\%), friends 233(55.1\%), teachers 216(51.1\%), and health professionals $179(42.3 \%)$. (Table 2$)$

Table 2. Knowledge on menstruation and menstrual hygiene of secondary school girl students, Wegera District, 2014.

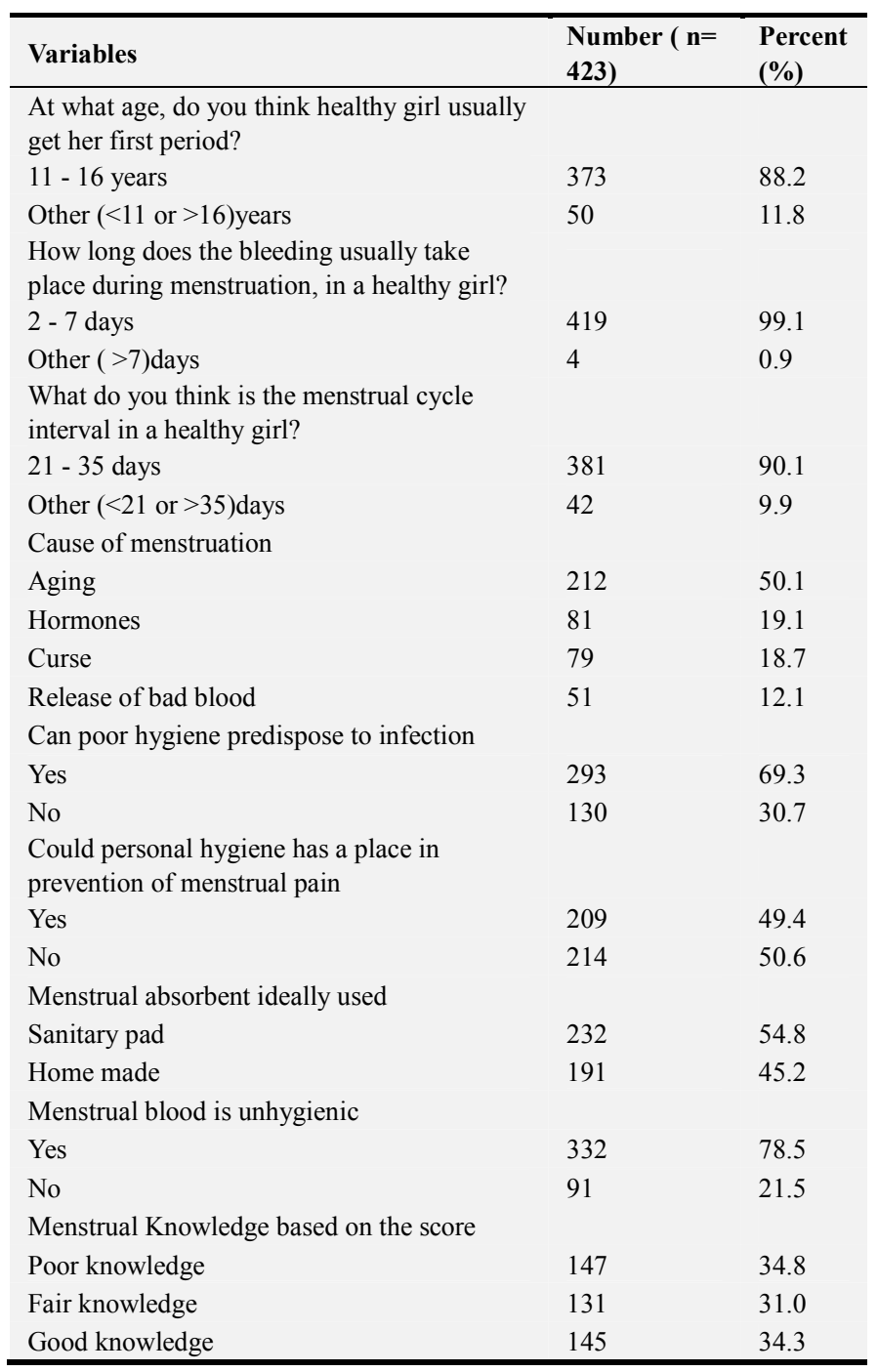




\subsection{Practice on Menstrual Hygiene of Secondary School Girl Students}

Majority of adolescent girls (77.5\%) were using homemade cloth and $22.5 \%$ were using sanitary pad during menstruation. Cleaning of external genitalia was reported by $(86.1 \%)$ of girls. However, for cleaning purpose, only 91(21.5\%) girls used both soap and water. About 207(48.9\%) of the girls reported that they changed their menstrual hygiene materials twice a day, $112(26.5 \%)$ of them did change once a day and $104(24.6 \%)$ of girls change three times and more. Three hundred twenty six (77.1\%) throw used menstrual soaking materials in the latrine and 38(9\%) throw used pad in the open field. Only 191(45.2\%) respondents take rest during menstruation. In general one hundred twenty six $(29.8 \%)$ of the respondents practiced good menstrual hygiene whereas $297(70.2 \%$ ) practiced poor menstrual hygiene.

\subsection{Factors Associated with Practice on Menstrual Hygiene}

Bivariate analysis showed that there was statistically significant association between menstrual practice and age of the respondents, grade level, prior information about menstruation before menarche, exposure to advertisement of sanitary products and knowledge on menstrual hygiene. After bivariate analysis, the factors of Good menstrual hygiene with p-value $<0.2$ were entered into the multivariate model. In multivariate analysis, there was statistically significant association between menstrual hygiene practice and exposure to advertisement regarding usage of sanitary napkins in mass media (radio/T.V) and knowledge on menstrual hygiene. The likelihood of good menstrual practice among girls who had exposure to advertisement is two times higher compared to girls who had no exposure to advertisement (AOR 2.06(1.27, 3.34). Girls with good knowledge on menstrual hygiene were two times more likely to have good practice when compared to girls with poor knowledge (AOR 2.23(1.06, 4.71). (Table 3)

Table 3. Factors independently associated with practice on menstrual hygiene of secondary school girl students, Wegere District, 2014.

\begin{tabular}{|c|c|c|c|c|c|}
\hline \multirow[t]{2}{*}{ Independent factors } & \multicolumn{2}{|c|}{ Menstrual practice } & \multirow[t]{2}{*}{ COR(95\% CI $)$} & \multirow[t]{2}{*}{$\operatorname{AOR}(95 \%$ CI) } & \multirow[t]{2}{*}{ P-value } \\
\hline & Good & Poor & & & \\
\hline Age & & & & & 0.117 \\
\hline $14-15$ & 10 & 53 & 1.00 & 1.00 & \\
\hline $16-17$ & 68 & 172 & $2.09(1.008,4.35)$ & $(0.764,3.656)$ & \\
\hline$>=18$ & 48 & 72 & $3.53(1.63,7.6)$ & $(1.012,5.686)^{*}$ & \\
\hline Grade level & & & & & 0.578 \\
\hline 9 & 53 & 167 & 1.00 & 1.00 & \\
\hline Permanent pocket money & & & & & 0.571 \\
\hline No & 47 & 139 & 1.00 & 1.00 & \\
\hline Yes & 79 & 158 & $1.47(0.96,2.26)$ & $(0.720,1.815)$ & \\
\hline Drinking water source & & & & & 0.306 \\
\hline Private & 27 & 45 & 1.00 & 1.00 & \\
\hline Public & 99 & 252 & $0.65(0.38,1.11)$ & $(0.761,2.382)$ & \\
\hline Prior information about & & & & & \\
\hline Yes & 112 & 233 & $2.19(1.18,4.08)$ & $(0.302,1.143)$ & \\
\hline Exposure to & & & & & \\
\hline advertisement & & & & & $0.005 *$ \\
\hline No & 80 & 239 & 1.00 & 1.00 & \\
\hline Yes & 46 & 58 & $2.36(1.49,3.76)$ & $0.493(0.302,0.806) *$ & \\
\hline Knowledge on & & & & & $0.015 *$ \\
\hline Menstrual hygiene & & & & & \\
\hline Poor knowledge & 25 & 122 & 1.00 & 1.00 & \\
\hline Fair knowledge & 43 & 88 & $1.81(0.92,3.53)$ & $1.893(1.04,3.44) *$ & \\
\hline Good knowledge & 58 & 87 & $3.53(1.77,7.03)$ & $2.37(1.31,4.288) *$ & \\
\hline
\end{tabular}

Note: $1.00=$ Reference $*=\mathrm{p}<0.05$

\section{Discussion}

In this study, 145(34.3\%) had good knowledge and $131(31 \%)$ had fair knowledge about menstrual hygiene. This finding is almost similar with the result of the study done in Nepal which showed that only $40.6 \%$ had good knowledge about menstrual hygiene (5). The finding is also lower than a study done in northwest Nigeria which indicated that $91.5 \%$ of the participants had high level of knowledge about menstrual hygiene (19). This difference might be due to the reason that mothers in the study area were illiterate and not interested to express their views and to educate their daughters about menstrual hygiene because of the taboo of discussing about menstruation.

The study shows that awareness of girls about menstruation before menarche was $81.6 \%$ which is almost the same as research done in Malawi $82 \%$ and $77 \%$ in Teheran $(2,19)$. In the present study $46.3 \%$ of girls reported mother as the first informant about menstruation and $44.4 \%$ 
reported friends as source of information, similar studies done in Malaysia in 2006 reported as $80 \%$ and $39.7 \%$ respectively (20). The difference noted may be due to poor literacy and cultural restrictions of mothers have fuelled the inhibitions a mother has to talk to her daughter regarding menarche and the significance of menstrual hygiene. In this study $54.8 \%$ of girls knew that sanitary products are available for menstrual protection which is lower compared to study conducted in Kano, Northwestern Nigeria most of the respondents $(94.0 \%)$ knew about it (19). This may be due to poor counseling of teachers, poor literacy level of mothers and availability of sanitary pads.

In the present study, $29.8 \%$ had good practice of menstrual hygiene. This is lower as compared with the study done in north western Nigeria which showed that $88.7 \%$ had good practice of menstrual hygiene (19). The gap observed may be due to difference in socio-economic status and availability and accessibility of sanitary products. About 207(48.9\%) of the girls reported that they changed their menstrual hygiene materials twice a day, $112(26.5 \%)$ of them did change once a day and 104(24.6\%) of girls change three times and more. Whereas similar study in Nigeria reported the majority $(60 \%)$ changed sanitary pads three times a day (14). The difference may be due to low socio-economic status to buy sanitary pad and soap, shortage of water and poor knowledge on menstrual hygiene.

The result of the present study revealed that exposure to advertisement of sanitary napkins was positively associated with menstrual hygiene practice. This finding was found consistent with the study on Paltagarh High School in Singur Block of Hoogly district, West Bengal [AOR 2.52(1.1-2.57)] (21).

Knowledge on menstrual hygiene was positively associated with practice on menstrual hygiene. This finding was consistent with other studies. A Cross Sectional Study among Female Adolescents in An Urban Slum of Mumbai, Significant association was observed between having good/fair knowledge and good practices $(p<0.01)$. Similarly a study in Nigeria found the association between knowledge of menstruation and menstrual hygiene practice $(\mathrm{p}<0.05)(12$, 16).

\section{Conclusions}

The knowledge of secondary school girls on menstrual hygiene was not adequate and the practices are often not optimal for proper hygiene. Exposure to advertisement regarding sanitary napkins and knowledge on menstrual hygiene were found to influence practice on menstrual hygiene of secondary school girls.

Development of a comprehensive school health education program and mass media should have an active role in raising the awareness of adolescent's flames about the physiological, psychological aspects of menstruation and the proper hygiene as well and creating an environment where girls could get menstrual hygiene materials with subsidized price within school premises.

\section{Acknowledgement}

We would like to acknowledge University of Gondar, Institute of Public health for giving this opportunity. We also thank wegera district education office and data collectors for their cooperation and assistance in the data collection. Finally we would like to extend our gratitude to the study participants who were fully cooperative for the study.

\section{References}

[1] Brumberg JJ., The body project: An Intimate History of American Girls. Random House Inc. New York,1997.

[2] Sarah House, Thérèse Mahon, and Sue Cavil. Menstrual hygiene matters. A resource for improving menstrual hygiene around the world First edition, 2012.

[3] Archana Patkar, Preparatory Input on MHM for End Group. WSSCC, May, 2011.

[4] WHO/UNFPA/UNICEF. Programming for Adolescent Health and Development., in Technical Report Series. 1999 Geneva.

[5] Adhikari P. Knowledge and practice regarding menstrual hygiene in rural adolescent girls of Nepal. Kathmandu University Medical Journal. 2007; 5(19): 382-386.

[6] El-Gilany A, Badawi K., El-Fedawy S. Menstrual hygiene among adolescent school girls in Mansoura. Egypt. Reprod Health Matters. 2005; 13(26): p. 147-52.

[7] Fund., U.N.C.s., useful information about menstrual health and hygiene, 2008. Child's Environment Section, UNICEF House, New Delhi, India.

[8] Unicef Innovation. Menstrual hygiene Management: A Supply Chain Challenge. September13 2013 URL http://unicefinnovation.org/challenge/menstrual-hygienemanagement-supply-chain-challenge.

[9] WSSCC. Celebrating Womanhood: Menstrual Hygiene Management. Water, Supply and Sanitation Collaboration Council, updated July 8th 2013. URL http://www.wsscc.org/topics/hygiene/menstrual-hygienemanagement.

[10] Abhay Bhausaheb Mudey, et al. A Cross-sectional Study on Awareness Regarding Safe and Hygienic Practices amongst School Going Adolescent Girls in Rural Area of Wardha District, India. Global Journal of Health Science. $2010 ; 2(2)$.

[11] Tania S., et al. Assessment of Beliefs and Practices Relating to Menstrual Hygiene of Adolescent Girls in Lebanon. International Journal of Health Sciences and Research. December 2013; 3; (12).

[12] Marni Sommer, et al. A comparison of the menstruation and education experiences of girls in Tanzania, Ghana, Cambodia and Ethiopia. A Journal of Comparative and International Education, 2014.

[13] Jarrah S. and Kamel A. Attitudes and practices of school-aged girls towards menstruation.. International Journal of Nursing Practice. 2012; 18(308-315). 
[14] Oche M. O., et al. Menstrual health: the unmet needs of adolescent girls' in Sokoto, Nigeria Department of Community Health, College of Health Sciences. Usmanu Danfodiyo University. 23 December, 2011.

[15] Lee LK, Chen PC. Lee KK, and Kaur J. Menstruation among adolescent girls in Malaysia: a cross-sectional school survey. Singapore Med J. 2006; 47 (10): 869-874.

[16] Sommer, M. 'Putting 'Menstrual Hygiene Management' into the School Water and Sanitation Agenda."Waterlines. 2010; 29 (4): p. 268-278.

[17] Prateek S, Saurabh R. A Cross Sectional Study of Knowledge and Practices about Reproductive Health among Female Adolescents in An Urban Slum of Mumbai. Journal of Family and Reproductive Health. December 2011; 5 (4).

[18] Poureslami, Mohammad, and F. Osati-Ashtiani. Assessing
Knowledge, Attitudes, and Behavior of Adolescent Girls in Suburban Districts of Tehran About Dysmenorrhea and Menstrual Hygiene. Journal of International Women's Studies. 2002; 3(2), 51-61.

[19] Lawan U, Yusuf N, Musa A. Menstruation and menstrual hygiene amongst adolescent school girls in Kano, Northwestern Nigeria. African Journal of Reproductive Health. 2010; 14(3):201-7.

[20] Khanna A, Goyal S R, and B. R. Menstrual Practices and Reproductive Problems: A Study of Adolescent Girls in Rajasthan. Journal of Health Management. 2005; 7 (1): 91107.

[21] Ray sudeshna and Dasgupta Aparajita. Determinants of menstrual hygiene among Adolescent girls: a multivariate analysis. national journal of community medicine. april-june 2012; 3(2). 